\title{
Para muestra un botón: ejemplos de animación sociocultural
}

Graciela Farrach ${ }^{1}$

El presente trabajo tiene como objetivo describir dos ejemplos de animación socio-cultural; uno en el entorno municipal y otro a nivel nacional. Para ejemplificar mejor, consideramos importante definir, a grandes rasgos, qué es la animación sociocultural.

Según Egg (2005), existe animación socio-cultural cuando se promueven y movilizan recursos humanos, mediante un proceso participativo, que desenvuelve potencialidades latentes en los individuos, grupos y comunidades. Partiendo de este concepto, describimos a continuación un ejemplo de animación sociocultural realizado en el municipio de San Rafael del Norte, Jinotega.

En el municipio en mención se realizaban fiestas tradicionales y religiosas en honor al Santo Patrono, San Rafael Arcángel. Hablamos en pasado porque a partir de 1990 se dejaron de realizar las tradicionales corridas de toros, chinamos, juegos infantiles, presentaciones circenses, etc. El motivo por el cual se suspendieron estas tradiciones fue el cambio de fecha de la celebración religiosa por parte del Concilio Vaticano II, presidido por Juan XXIII, en mil novecientos setenta y dos. En ese entonces se dispuso celebrar a San Rafael Arcángel el 29 de septiembre y no el 24 de octubre, fecha en que por años se festejó con muestras de expresión religiosa y tradiciones culturales.

Muy a pesar de las disposiciones de la Santa Sede, los pobladores continuaban celebrando sus fiestas patronales, haciendo caso omiso a las disposiciones eclesiásticas. Pero todo cambió en 1990, al asumir el gobierno de Doña Violeta Barrios de Chamorro, la Iglesia obedeció al pie de la letra, trasladando la celebración. Es así que, la tradición pasó a formar parte del recuerdo de los sanrafaelinos, que solamente se limitaban a cuestionar la imposición eclesial.

Pero, de 2013 a la fecha, los sanrafaelinos volvieron al rescate de sus tradiciones ancestrales, gracias al trabajo coordinado entre la Alcaldía municipal, la Iglesia Católica, el gabinete de la familia y población en general. Se realizaron diversas actividades recreativas y culturales en las que fue notoria la participación de pobladores, sobre todo de niños y jóvenes, que por primera vez presenciaban este tipo de eventos. La actividad que más llamó la atención fue "El arca de Noé”, en la que se colectaron donativos de todo tipo entre la población, desde ganado en pie, cerdos, gallinas y granos básicos, hasta electrodomésticos. Luego estos productos fueron adquiridos por los pobladores por un valor de diez córdobas. Lo recaudado se destinó a la realización de obras sociales y religiosas.

Además se realizó exposición de artesanías, elección y coronación de la reina de las fiestas patronales, desfile hípico, tertulia, fiesta popular y un espacio de entretenimiento a la niñez y juventud promovido por la municipalidad, que donó a la población un día de juegos mecánicos del Play Land Park Internacional. Como lo explica Rivera (2013), “ ¡Con unidad y entendimiento se logró el abrazo con nuestra historia!”

1 Estudiante de Doctorado en Educación e Intervención Social en UNAN-Mangua. Correo Electrónico: gfarrach@gmail.com 
Por otro lado, en el contexto nacional, citaremos otro ejemplo de animación socio-cultural, como es el Programa Educativo, Laboral, de Salud y Cultural del Adulto Mayor (PELSCAM), que desde 2007 impulsa el Instituto Nicaragüense de Seguridad Social (INSS). Este tiene su fundamento en la Ley orgánica de la Seguridad Social en Nicaragua, que establece el desarrollo de programas para brindar una vejez alternativa, para una mejor adaptación a las condiciones de vida de las personas jubiladas.

El PELSCAM se caracteriza por promover la formación educativa sobre aspectos bio-psico-sociales del proceso de envejecimiento, potenciando una cultura de envejecimiento activo, digno, saludable y exitoso. Al mismo tiempo, el programa permite la mejora de los ingresos económicos y de la calidad de vida de los beneficiarios, a través de su participación en proyectos productivos, con fondo semilla revolvente, que les permite la inserción al mercado laboral. En el aspecto de salud, el programa monitorea y supervisa los establecimientos de salud en los que se atienden al adulto mayor, con miras a la mejora de este servicio.

En el ámbito cultural, se promueven actividades recreativas y culturales con adultos mayores, encaminadas a rescatar la identidad, autoestima, experiencia y capacidad de las personas de la tercera edad. De ahí que, entre los resultados de impacto reflejados en la ejecución del PELSCAM están: presentaciones artísticas de jubilados, incluyendo en el Teatro Nacional Rubén Darío; charlas educativas sobre salud, nutrición y autoestima; participación de adultos mayores en iniciativas productivas y expo-venta de productos elaborados por ellos mismos.

Retomando la definición de Egg (2005), podemos decir que las actividades mencionadas son ejemplos de animación socio-cultural, porque involucran a los individuos; al tiempo que desarrollan en ellos potencialidades latentes, partiendo de un proceso participativo que involucra al gobierno, la comunidad, instituciones religiosas, partidos políticos, entre otros; de una forma coordinada y con miras no sólo a la recreación, sino también al rescate de las tradiciones culturales y religiosas.

\section{BIBLIOGRAFÍA}

Egg, A. (2005) Perfil del animador socio-cultural. Buenos Aires: Lumen Hvmanitas.

Instituto Nicaragüense de Seguridad Social (2013) Programa Educativo, Laboral, de Salud, y Cultural del Adulto Mayor. Disponible en http://www.inss.gob.ni/index.php/programas-35/pelscam

Rivera, A. (2013). Nos reconciliamos con la historia. E1 Nuevo Diario. 31 de octubre de 2013. Disponible en: http://www.elnuevodiario.com.ni/opinion/300641-reconciliamos-historia. 